\title{
FLUORIDE RETENTION IN HUMAN ENAMEL AFTER A SINGLE PHOSPHORIC ACID AND MIXED PHOSPHORIC ACID/SnF 2 APPLICATION IN VITRO
}

\author{
P. G. E. Kalter, T. D. Flissebaalje and A. Groeneveld \\ Caries Research Unit, Health Organization TNO, Laboratory for Microbiology,
} University of Utrecht. The Netherlands

\begin{abstract}
Summary-Pieces of enamel were treated with either an APF solution or a 1:1 mixture of $\mathrm{APF} / \mathrm{SnF}{ }_{2}$ (APF: 1.23 per cent $\mathrm{F}^{-}, 0.1 \mathrm{M} \mathrm{H}_{3} \mathrm{PO}_{4}$; and $\mathrm{SnF}_{2}: 2$ per cent) for $4 \mathrm{~min}$ at $37^{\circ} \mathrm{C}$ followed by $30 \mathrm{~min}$ washing. There was an increase of 1640 parts $/ 10^{6}$ in the fluoride concentration of APF-treated enamel. Most of the fluoride was, however, washed away within $24 \mathrm{~h}$ to a level of 230 parts $/ 10^{6}$. After $7 \times 24 \mathrm{~h}$ the $\mathrm{F}$ concentration was of the same order: 280 parts $/ 10^{6}$. The initial increase in fluoride concentration was lower after a mixed topical application $\left(1120\right.$ parts $\left./ 10^{6}\right)$ but after $24 \mathrm{~h}$ the fluoride concentration was 510 parts and after $7 \times 24 \mathrm{~h}$ 370 parts $/ 10^{6}$, although statistically not significant, higher than after a single APF-treatment. The higher $F$ concentration may be due to the formation of more firmly-bound fluoride as a fluoridated hydroxyapatite. It is more probable that the $\mathrm{CaF}_{2}$ layer is protected by insoluble $\mathrm{Sn}$ compounds.
\end{abstract}

\section{INTRODUCTION}

Topical applications of concentrated fluoride solutions are widely used in caries prevention. The solutions initially used were mainly of $\mathrm{NaF}$ and $\mathrm{SnF}_{2}$. Brudevold et al. (1963) showed that there was higher F-uptake when NaF-solution was acidified with phosphoric acid (APF). Caslavska et al. (1971) showed that using $\mathrm{NH}_{4} \mathrm{~F}$-solution increased initial $\mathrm{F}$ uptake further, as did acid pre-treatment (Aasenden, Brudevold and McCann, 1968). The disadvantage of a high initial F-uptake is, however, that only a few per cent is deposited as firmly-bound fluoride (Caslavska, Moreno and Brudevold, 1975a). The remainder is mainly present as $\mathrm{CaF}_{2}$ which leaches out relatively quickly and may, in consequence, be of little use in caries reduction.

Shannon (1970) found that the application of APF and $\mathrm{SnF}_{2}$ solutions sequentially produced greater enamel solubility reduction than when either was used separately. Kleinstub and Shannon (1974) showed that is true also with a freshly prepared mixture of $\mathrm{APF}$ and $\mathrm{SnF}_{2}$ and suggested that $\mathrm{CaF}_{2}$ was formed in both cases together with a tenacious layer of insoluble Sn-compounds. As most of the fluoride present as $\mathrm{CaF}_{2}$ disappears rapidly after a single APF-treatment, we wondered whether the $\mathrm{CaF}_{2}$ formed after a mixed application of $\mathrm{APF} / \mathrm{SnF}_{2}$ is protected by insoluble $\mathrm{Sn}$-compounds and could therefore act as a fluoride reservoir. Our purpose here was to measure the amount of retained fluoride in enamel after washing. As $\mathrm{pH}$ fluctuations in the presence of fluoride increase the amount of fluoridated apatite (Duff, 1976; Duke and Forward, 1977), we investigated this aspect also.

\section{MATERIALS AND METHODS}

Incisor and canine teeth from subjects living in a non-fluoridated area were used. The teeth were stored in a solution of 2 per cent cetrimide (Cetavlon) in tap water and lightly cleaned with pumice before treatment. A rectangular piece of known size was sawn at random from the buccal surface as a control. Cervical regions were excluded. The remainder of the tooth was cut longitudinally into two halves.

\section{Treatment}

Each series of 10 half teeth was fixed on sticky wax and dried for $1 \mathrm{~min}$. The teeth then received either (1) a 4 min APF treatment at $37^{\circ} \mathrm{C}$, or (2) a 4 min APF $\mathrm{SnF}_{2}$ treatment at $37^{\circ} \mathrm{C}$. The composition of the APF was: total $\mathrm{F} 1.23$ per cent; $\mathrm{H}_{3} \mathrm{PO}_{4} 0.1 \mathrm{M}$, pH $=3$. The APF $/ \mathrm{SnF}_{2}$ mixture was prepared directly before use by mixing APF and a freshly prepared 2 per cent $\mathrm{SnF}_{2}$ solution in a $1: 1$ ratio with a resultant $\mathrm{pH}$ of 2.1.

The tooth halves were dried for $0.5 \mathrm{~min}$ and subsequently washed for $3 \times 10 \mathrm{~min}$ in $100 \mathrm{ml}$ of tap water. After further washing for $24 \mathrm{~h}$ in tap water and twicedaily changed for 7 days in $100 \mathrm{ml}$ of a solution containing $0.001 \mathrm{M} \mathrm{Ca}$ and $0.0025 \mathrm{M} \mathrm{PO}_{4}$ at a pH of 5.5 (concentrations comparable with those in saliva, added to prevent dissolving of the enamel apatite), $\mathrm{F}$ was estimated in the outer layers of enamel.

In a second series of experiments, enamel was treated with a mixed $\mathrm{APF} / \mathrm{SnF}_{2}$ for $4 \mathrm{~min}$ at $37^{\circ} \mathrm{C}$. Fluoride estimations of two enamel layers were carried out after a 24-h $1 \mathrm{M} \mathrm{KOH-treatment} \mathrm{preceded} \mathrm{by}$ either $0.5 \mathrm{~h}$ washing, $7 \times 24 \mathrm{~h}$ storage at a constant $\mathrm{pH}$ of 6.5 or $7 \times 24 \mathrm{~h}$ of cyclical $\mathrm{pH}$ fluctuations. One $\mathrm{pH}$ cycle was completed each day; the tooth halves were immersed in the washing solution for $5 \mathrm{~min}$ at $\mathrm{pH}=3.5$. This was followed by humid storage for $8 \mathrm{~h}$ at $37^{\circ} \mathrm{C}$. This treatment was then repeated at $\mathrm{pH}=8.0$ and followed by $16 \mathrm{~h}$ humid storage.

\section{Embedding procedure}

Pieces of buccal enamel with a surface area of between 2.5 and $5 \mathrm{~mm}^{2}$ were sawn from similar pos- 
itions in each pair of tooth halves. The surface area was estimated from precision micrometer measurements. The experimental and control blocks were embedded in a fast-polymerising two-component poly-acrylate under 2 atmosphere pressure. When polymerization was complete, the embedded enamel pieces were washed for a few seconds in distilled water and alcohols. There was no measurable gap between the enamel and the polymer under a $\times 500$ magnification.

\section{Chemical analysis}

The first of two enamel layers was removed by holding the samples in a plastic vial containing $0.5 \mathrm{ml}$ $0.5 \mathrm{M} \mathrm{HClO}_{4}$ for $30 \mathrm{~s}$. The surface was then washed in $1.5 \mathrm{ml} \mathrm{H}_{2} \mathrm{O}$ and the two fractions combined. A second layer was then removed in the same way. The fluoride concentration in the acid solution was estimated by a modification of the gas-chromatographic method described by Fresen, Cox and Witter (1968): $0.5 \mathrm{ml}$ solution F-unknown $+0.05 \mathrm{ml}$ benzene-trimethylchlorsilan (TMCS) $+0.05 \mathrm{ml} \mathrm{HCl} 25$ per cent were used. The following quantities were used in the extraction procedure originally described by Fresen et al.: $2 \mathrm{ml}$ solution F-unknown $+1.0 \mathrm{ml}$ benzene-TMCS $+1.0 \mathrm{ml}$ $\mathrm{HCl} 25$ per cent.

By accurate working in special conical plastic tubes, it was possible to estimate $F$ concentrations as low as $0.002 \mu \mathrm{g} / \mathrm{ml}$. The modified method was tested in the range of $0.002-0.01 \mu \mathrm{g} \mathrm{F} / \mathrm{ml}$ and $0.01-0.1 \mu \mathrm{g}$ $\mathrm{F} / \mathrm{ml}$. A linear relationship between $\mathrm{F}$ concentration and relative peak-length was demonstrated in both cases.

The calcium concentration was estimated spectrophotometrically as described by Gindler and King (1972) on $0.1-0.5 \mathrm{ml}$ of the acid solution after neutralization with $\mathrm{KOH}$. Phosphate was estimated by the method of Chen, Toribara and Huber (1956).

\section{Calculation}

The weight of dissolved enamel $\left(W_{e}\right)$ was calculated from the phosphate concentration in $\mu \mathrm{g} / \mathrm{ml}$ assuming a phosphate percentage in enamel of 17 per cent.

$$
W_{e}=2 \times\left(\mathrm{PO}_{4}^{3-}\right) \times \frac{100}{17} .
$$

The thickness of the corresponding enamel layer in $\mu \mathrm{m}$ was calculated from the enamel surface area $\left(\mathrm{mm}^{2}\right)$ and the enamel density $(d)$ which was assumed to be 2.95 .

$$
d=\frac{W_{e}}{2.95 \times \text { surface area }} .
$$

The mean $F$ percentage in each layer was estimated from the total amount of fluoride $W_{f}$ and the corresponding enamel weight:

$$
F_{\mathrm{ppm}}=\frac{W_{f}}{W_{e}} \times 10^{6}
$$

The $F$ percentage of different samples should not be directly compared because of varying layer thickness. The $F$ percentage at a standard depth is calculated by constructing an $F$ gradient by linear interpolation, but this method is not entirely correct (Mühlemann, Schait and König, 1964). In our experiment, the F gradients were constructed on the assumption that

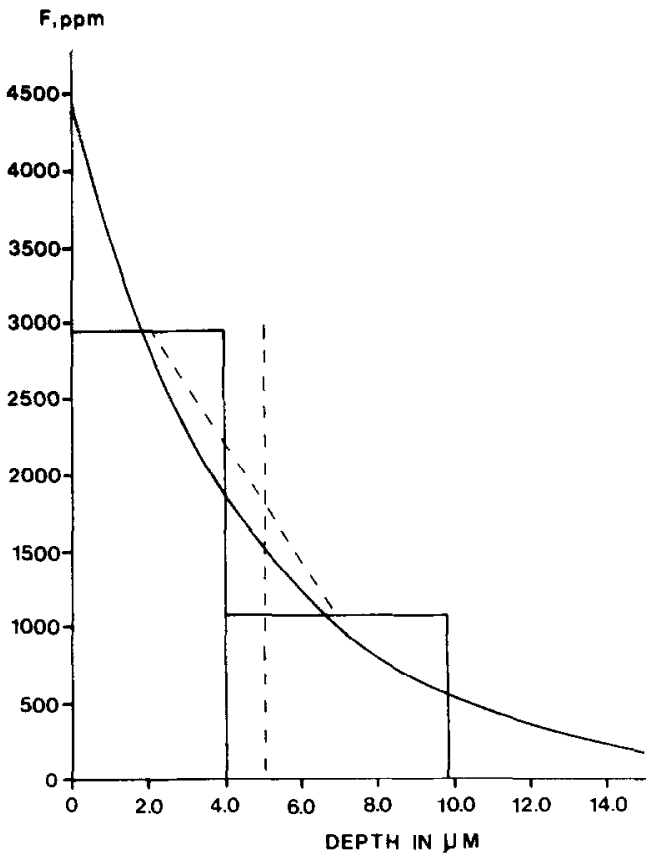

Fig. 1. The F gradient constructed from the F percentages of two enamel layers ( - . . ). The linear interpolation approach is given by the dotted line $(\ldots-)$. Note the difference in the $F$ percentage at $5 \mu \mathrm{m}$ estimated by linear interpolation and the calculated $F$ gradient.

they have an exponential path (Fig. 1). The F percentage at a depth of $5 \mu \mathrm{m}$ was estimated by assessing the function:

$$
F=F_{0} \cdot \imath^{\cdots k d}
$$

which expresses the $F$ percentage at an enamel depth $d$ : $F_{0}$ being the $F$ percentage at the enamel surface and $k$ a constant. This function was estimated from the mean $F$ percentages $F_{1}$ and $F_{2}$ of the first two enamel layers. $d_{1}$ and $d_{2} \mu \mathrm{m}$ thick respectively, by using 2 equations:

$$
\begin{aligned}
& \int_{0}^{d_{1}} F_{0} \cdot \mathrm{e}^{-k d}=F_{1} \cdot d_{1} \\
& \int_{d_{1}}^{d_{2}} F_{0} \cdot \mathrm{e}^{-k d}=F_{2} \cdot\left(d_{2}-d_{1}\right) .
\end{aligned}
$$

$\mathrm{F}_{0}$ and $k$ were first calculated using a computer program. The $F$ function and the $F$ percentage at $5 \mu \mathrm{m}$ could then be estimated.

This method is only applicable for $F$ percentages within the total etched depth. The $F$ increase at a depth of $5 \mu \mathrm{m}$ was estimated from the $\mathrm{F}$ percentage of the treated and control enamel samples using this technique.

\section{RESULTS}

All the available $\mathrm{CaF}_{2}$ in APF-treated enamel was washed away within $24 \mathrm{~h}$ (Table 1). The remaining $\mathrm{F}$ increase, present as a firmly-bound insoluble fluoride compound, was about 250 parts $/ 10^{6}$ after $24 \mathrm{~h}$ washing and remained at this level even after 7 days.

The initial $F$ uptake of APF/SnF ${ }_{2}$-treated enamel was much lower than that which occurred after an APF-application, but after washing for $24 \mathrm{~h}$ nearly 
Table 1. Difference in $F$ concentration compared with the control values at a depth of $5 \mu \mathrm{m}$ after different washing periods, in enamel treated with APF and $\mathrm{APF} / \mathrm{SnF}_{2}$ at $37^{\circ} \mathrm{C}$ for $4 \mathrm{~min}$

\begin{tabular}{crrl}
\hline $\begin{array}{c}\text { Washing period } \\
(\mathrm{h})\end{array}$ & APF & APF $/ \mathrm{SnF}_{2}$ & \multicolumn{1}{c}{ Difference } \\
\hline$\frac{1}{2}$ & $1640(540)$ & $1120(840)$ & $-520 p \leqslant 0.1$ \\
24 & $230(230)$ & $510(350)$ & $+280 p=0.1$ \\
$7 \times 24$ & $280(260)$ & $370(210)$ & +90 n.s. \\
\hline
\end{tabular}

Standard deviations given in brackets.

n.s. = not significant.

half was still present. Washing for 7 days resulted in a further decrease in the F-content, demonstrating that $24 \mathrm{~h}$ washing did not remove all soluble fluoride com. pounds. There was no significant increase in firmlybound fluoride in $\mathrm{APF} / \mathrm{SnF}_{2}$-treated enamel either after storage for 1 week at a constant $\mathrm{pH}$ or with $\mathrm{pH}$ fluctuations (Table 2). In both, the amount of fluoride deposited was similar to that found after an $\mathrm{APF} / \mathrm{SnF}_{2}$ treatment followed by a $24-\mathrm{h} \mathrm{KOH}-$ extraction.

\section{DISCUSSION}

The $F$ percentages were calculated on the assumption that the $\mathbf{F}$ gradient follows an exponential path (Fig. 1) based on Mühlemann's (1961) observation that the shape of the F gradient is concave. A single exponential function was chosen to approximate the $\mathrm{F}$ gradient. The F-values calculated with linear interpolation tend to be some 20 per cent higher.

Our results show that the $\mathrm{CaF}_{2}$ layer is retained for longer after an $\mathrm{APF} / \mathrm{SnF}_{2}$ treatment than after a single APF treatment and can, in consequence, serve as a temporary fluoride reservoir. We have assumed that the soluble fluoride compounds formed after an $\mathrm{APF} / \mathrm{SnF}_{2}$ treatment consist solely of $\mathrm{CaF}_{2}$, as the $\mathrm{Sn}$ compounds formed are insoluble (Wei, 1975). Our results agree with experiments using electronmicroscopy after either a sequential APF/ $\mathrm{SnF}_{2}$ or an APF treatment, both followed by 24 -h washing (Wei, 1975). As the formation of a fluoridated apatite (FHAP) occurs quite slowly, the continued presence of $\mathrm{CaF}_{2}$ may be beneficial (Mühlemann, 1967).

- A few per cent only of the fluoride initially present after an APF treatment is firmly bound (FHAP) and appears to be independent of the amount of $\mathrm{CaF}_{2}$ initially present, whereas the presence of $\mathrm{CaF}_{2}$ for a longer period results in a slow increase in the percent-

Table 2. Difference in $F$ concentration comparcd with the control values at a depth of $5 \mu \mathrm{m}$ after different procedures. Enamel treated with $\mathrm{APF} / \mathrm{SnF}_{2}$ at $37^{\circ} \mathrm{C}$ for $4 \mathrm{~min}$

\begin{tabular}{cc}
\hline Treatment & APF $/ \mathrm{SnF}_{2}$ \\
\hline KOH & $370(330)$ \\
pH fluctuation $(3.5-8.0)+\mathrm{KOH}$ & $440(350)$ \\
constant $\mathrm{pH}=6.5+\mathrm{KOH}$ & $410(400)$ \\
\hline
\end{tabular}

Standard deviations given in brackets. age of FHAP (Caslavska, Moreno and Brudevold, 1975b). The bulk of the $\mathrm{CaF}_{2}$ would be quickly washed away unless protected, and is therefore of little value. We therefore followed the $F$ applications with $\frac{1}{2} \mathrm{~h}$ washing. The $\mathrm{F}$ increases recorded after APF treatment are, in consequence, lower than the values of the unwashed samples of Wei and Schulz (1975).

The roles played by FHAP and $\mathrm{CaF}_{2}$ in caries protection are complicated. Caslavska et al. (1975a) suggested that the effectiveness of a topical treatment depends on the amount of fluoride incorporated as FHAP. Clinical investigations by Wellock and Brudevold (1963) showed that there is a greater caries reduction after an APF treatment than after $\mathrm{NaF}$ and this may be caused by the $\mathrm{CaF}_{2}$ layer. However, Wei and Schulz (1975) found, in vivo, that a high initial F level $\left(20,000\right.$ parts $\left./ 10^{6}\right)$, probably caused by $\mathrm{CaF}_{2}$ formed after an acid pre-treatment and APF application, decreased to a value below that of the original untreated level after 3 months, showing that the longterm effects of techniques producing high initial $F$ uptake are not necessarily beneficial.

The concentration of FHAP we recorded after APF treatment followed by $24 \mathrm{~h}$ washing is similar to that reported by Caslavska et al. (1975b). The amount of firmly-bound fluoride, formed after an $\mathrm{APF} / \mathrm{SnF} \mathrm{F}_{2}$ treatment is, however, higher and probably consists mainly of FHAP, although stannous-fluoride phosphate compounds and protected $\mathrm{CaF}_{2}$ may also be present.

We used $\mathrm{pH}$ fluctuations and humid storage after $\mathrm{APF} / \mathrm{SnF}_{2}$ treatment to simulate the in vivo situation. There was, however, no increase in the amount of firmly-bound fluoride. We expected slow dissolution of $\mathrm{CaF}_{2}$ to result in the formation of more FHAP, especially in conditions of fluctuating $\mathrm{pH}$, as Duff (1976) demonstrated for APF-treated enamel. One reason for this negative result might be that a protective layer of $\mathrm{Sn}$ compounds could inhibit diffusion.

$\mathrm{APF} / \mathrm{SnF}{ }_{2}$ treatments have, until now, been tested mainly on the basis of enamel solubility reductions. Our results also demonstrate that $\mathrm{CaF}_{2}$ formed after mixed $\mathrm{APF} / \mathrm{SnF}_{2}$ applications may be protected by insoluble $\mathrm{Sn}$ compounds, it therefore washes out more slowly,

\section{REFERENCES}

Aasenden R., Brudevold F. and McCann H. G. 1968. The response of intact and experimentally altered human enamel to topical fluoride. Archs oral Biol. 13, 543-552. 
Brudevold F. Savory A., Gardner D. E., Spinelli M. and Speirs R. 1963. A study of acidulated fluoride solutions. I. In vitro effects on enamel. Archs oral Biol. 8, 167-177.

Caslavska V., Brudevold F., Vrbic V. and Moreno E. C. 1971. Response of human enamel to topical application of ammonium fluoride. Archs oral Biol. 16, 1173 1180 .

Caslavska V. Moreno E. C. and Brudevold F. 1975a. Determination of the calcium fluoride formed from in vitro exposure of human enamel to fluoride solutions. Archs oral Biol. 20, 333-339.

Caslavska V.. Moreno E. C. and Brudevold F. 1975b. Apatitic fluoride produced by various topical fluoride treatments. AADR. Program and Abstracts of Papers, Abstract 541 .

Chen P. S., Toribara T, Y. and Warner Huber. 1956. Microdetermination of phosphorus. Analyt. Chem. 28, 1756-1758.

Duff E. J. 1976. Fluoride incorporation into powdered human enamel under conditions of fluctuating $\mathrm{pH}$. Caries Res. 10, 234-240.

Duke S. and Forward G. C. 1977. Factors affecting the activity of topical fluoride treatments. Caries Res. 11, 126. Abstract.

Fresen J. A. $\operatorname{Cox} F$. H. and Witter M. J. 1968. The determination of fluoride in biological material by means of gas chromatography. Pharm. Weekbld. 103, 33, 909.
Gindler E. M. and King J. D. 1972. Rapid colorimetric determination of calcium in biologic fluids with methylthymol blue. Am. J. clin. Path. 58, 376-382.

Kleinstub P. H. and Shaunon I. L. 1974. Increasing tooth resistance by treatment with a mixture of fluorides. Milit. Med. 39, 722-724.

Mühlemann H. R. 1967. Die Kariesprophylaktische Wirkung der Aminfluoride. Sonderdruck aus Quintessenz Vols 5-8, Abstract 3192

Mühlemann H. R.. Schait A and König K. G. 1964. A chemical method for the removal of enamel surface layers and its suitability for fluoride analysis. Helv. odont. Acta 8, 147-153.

Shannon I. L. 1970. In vitro enamel solubility reduction through sequential application of acidulated phosphofluoride and stannous fluoride. J. Can. dent. Ass. 8, 308-310.

Wei S. H. Y. 1975. Effect of topical fluoride solution on the enamel surface as studied by scanning electron microscopy. Caries Res. 9, 445-458.

Wei S. H. Y. and Schulz E. M. 1975. In vivo microsampling of enamel fluoride concentrations after topical treatments. Caries Res. 9, 50-58.

Wellock W. D. and Brudevold F. 1963. A study of acidutated fluoride solutions. II. The caries inhibiting effects of single annual topical applications of an acidic fluoride and phosphate solution. A $2 \mathrm{yr}$ experience. Archs oral Biol. 8, 179-182. 